\title{
THE EIS OPTIONS AT MONITORING THE SPREAD OF POLLUTION IN THE STREAM
}

\author{
Jana Pař́lková ${ }^{1}$, Zbyněk Zachoval ${ }^{1}$, Jan Jandora ${ }^{1}$, Šimon Pošpíšilík ${ }^{1}$, Jan Mikulka $^{2}$, Jan Dušek ${ }^{2}$, David \\ Juřička $^{3}$, Boriss Gjunsburgs ${ }^{4}$, Algirdas Radzevičius ${ }^{5}$ \& Rytis Skominas ${ }^{5}$ \\ ${ }^{1}$ Brno University of Technology, Faculty of Civil Engineering, Institute of Water Structures, Veveř́ 331/95, 60200, \\ Brno, Czech Republic, e-mail address: parilkova.j@fce.vutbr.cz \\ ${ }^{2}$ Brno University of Technology, Faculty of Electrical Engineering and Communication, Department of Theoretical and \\ Experimental Electrical Engineering, Technická 3082/12, 61600, Brno, Czech Republic, e-mail address: \\ mikulka@feec.vutbr.cz \\ ${ }^{3}$ Mendel University in Brno, Faculty of Forestry and Wood Technology, Department of Geology and Pedology, \\ Zemědělská 3, 61300, Brno, Czech Republic, e-mail address: david.juricka@ mendelu.cz \\ ${ }^{4}$ Riga Technical University, Department of Water Engineering and Technology, Kipsala Str. 6A, LV-1048, Riga, \\ Latvia, e-mail address: boriss.gjunsburgs@gmail.com \\ ${ }^{5}$ Vytautas Magnus University, Institute of Hydraulic Engineering. Universiteto Str.10, LT-53361, Kaunas distr., \\ Lithuania, e-mail address: algirdas.radzevicius@vdu.lt
}

\begin{abstract}
Water pollution is one of the most significant problems in the world today and is a global problem. Surface water pollution in streams and reservoirs is reflected in the deterioration of the quality of aquatic ecosystems, including those that occur in their vicinity or follow them. Lack of quality drinking water is one of the main causes of various diseases, which can lead to death, especially in developing countries. Therefore, it is important to detect water pollution in time and anticipate how it could develop and be transported in the stream. Measurements on a physical model are time-consuming and economically demanding, but for a given locality it can provide comprehensive information, including the proposal of possible measures and their verification. It is also a suitable approach for calibration and verification of mathematical models. One of the main tasks in the physical modelling of the spread of pollution in the stream was to find a suitable substance that would simulate the pollution without being aggressive towards the water pumping circuit. The method of electrical impedance spectrometry was chosen for its detection in the stream.
\end{abstract}

Key words: pollution, water, stream, electrical impedance, physical model.

\section{INTRODUCTION}

Water is a phenomenon which, together with air and soil, represents the basic conditions of life on Earth and has accompanied humanity since the beginning of its existence. It is a very important raw material, a substance mediating transport, a building material for the bodies of living organisms, a valued commodity and a tool for relaxation and the implementation of leisure activities and other activities. Natural water sources can be divided into surface and subsurface and they are water sources that can be used as a source of drinking water for the population or in the technological process (irrigation, supply, etc.). At present, developed industry, agriculture and other fields of human activity, including significant interventions in nature and the alternation of dry periods with torrential rains, floods and tornadoes, water quality is degraded.
The main division of water pollution can be considered the division according to sources, i.e. local pollution, which can involve households, businesses, farms and the like, and pollution of territorial units, where the behaviour of polluters can be transmitted to other entities, such as flushing fertilizers and pesticides from fields including their penetration into groundwater.

Another classification factor assessing pollution may be its origin. Here we can basically talk about biological, chemical and physical pollution. While biological pollution of water is caused mainly by organic substances (faeces, silage liquids, etc.) and in the case of physical pollution it is mainly pollution by radioactive radiation (e.g. during uranium mining or storage), thermal pollution e.g. during drainage of cooling water from power plants and mechanical pollution, e.g. aggradation of rivers and reservoirs, in the case of chemical pollution it is a whole complex of possible 
causes of its formation with a significant risk of possible identification and its consequences, because pollutants may not always be easily observable in water.

Among the most basic forms of chemical pollution can be pollution of oil and oil products, where the substances form a thin film on the water surface, preventing water oxidation and damaging bird feathers and animal fur. It is also a category of substances found mainly in detergents and cleaning agents, so-called surfactants, which are surface-active, prevent gas exchange and are toxic. If they contain phosphates, they cause water eutrophication. Another large group is polychlorinated biphenyls, which are part of hydraulic fluids, paints and lubricants. They are toxic and carcinogenic substances that settle in adipose tissue and seriously damage the immune system, nervous system and skin. The application of fertilizers and pesticides remains a current problem, although their use is limited and controlled. However, from metals and immissions, heavy metals enter the waters, which accumulate in reservoirs, into the organisms of fish and waterfowl and through them also humans. A similar phenomenon is represented by drugs. Therefore, it is important to detect water pollution in time, identify its source, anticipate its development and transport in the stream and apply measures leading to its disposal and remediation, which will be most suitable for a given type of pollution and location from both an ecological and economic point of view.

Despite the considerable complexity of the phenomenon of the spread of pollution in a watercourse, two main tools are offered for its at least partial prediction, namely physical and mathematical modelling. Both approaches must respect the design rules and represent certain specifics of the results presentation. The paper presents the results obtained by physical modelling [1, 2, 3, 4] of water pollution transport. This approach is very time-consuming, it requires the background of a laboratory [5] with pumping equipment with distribution circuits and sufficient water capacity, measuring equipment and knowledge and experience of the operator, both in terms of craft, technical and scientific. It is obvious that the economic demands are not negligible either. However, a certain benefit of physical modelling is, in addition to monitoring and examining the required one, also the possibility of using it for calibration and verification of mathematical models.

One of the measuring techniques that has the potential to document the spread of pollution in a stream is the method of electrical impedance spectrometry $[6,7$, $8,9,10,11]$.

\section{METHOD AND MATERIAL}

To solve the problem of the spread of pollution in watercourses by the method of physical modelling, a physical model of the river Opava was used [12], which arises at the confluence of three streams Black Opava, Middle Opava, and White Opava near Vrbno under the Praděd (Czech Republic). The streams originate on the main ridge of Rough Jeseník and flow down at an altitude of $550 \mathrm{~m}$ above sea level (Baltic height system). Opava flows from the left into the Odra. In the upper part, the river has a stony bed with a large slope and relatively overgrown banks, after floods in the riverbed are often infested trees. Weirs and drop structures mitigate the steep slope.

The Opava River is a stream with a significant transport of sediments. It transports both the bed load and suspended load. Part of the transport is also particles floating mainly of organic origin and flushing (washing) from the soil of very fine particles - wash load. The transport of sediments is uneven and unstable over time, even with a steady flow of water. Due to aggradation and degradation, there are changes in the shape of the riverbed, causing changes in the flow of water and subsequently an uneven flow of sediments. With a unsteady flow of water, the unevenness and instability of the transport of sediments is more significant. A substance simulating pollution was dosed into these complex water and sediment flow conditions.

The physical model was built on the basis of the principles of model similarity while respecting the limits of similarity and accepting appropriate simplifications. The length scale $\mathrm{M}_{l}=30$ of the model was determined so that the model was spatially undistorted, i.e. geometrically similar (orthogonal coordinate system with axes $x, y, z)$

$$
M_{x}=M_{y}=M_{z}=M_{l}=30 .
$$

It was modelled according to Froud's criteria

$$
F r=\frac{v}{(g \cdot l)^{1 / 2}},
$$

thus on the basis of the principle of the dominant force, which is the force of gravity $F_{g}$. In the case of using the same liquid (on the model and on the prototype, density $\rho=$ const., kinematic viscosity $v=$ const.), the same grain density $\rho_{s}$ and under the action of the same acceleration due to gravity $g$, other considered quantities $(A)$ were determined using the length scale $M_{l}$. The conversion from prototype to model can then be performed according to the relationship

$$
A_{\text {prototype }}=M_{l} \cdot A_{\text {model }} .
$$

The physical model was built in a river trough connected to the water recirculation circuit, it is built of a concrete skeleton with a movable bottom formed partly by sand and partly by fine-grained gravel (Fig. 2). Both the bottom and the banks of the watercourse are modelled to simulate the roughness of the riverbed. 
Table 1 The flows

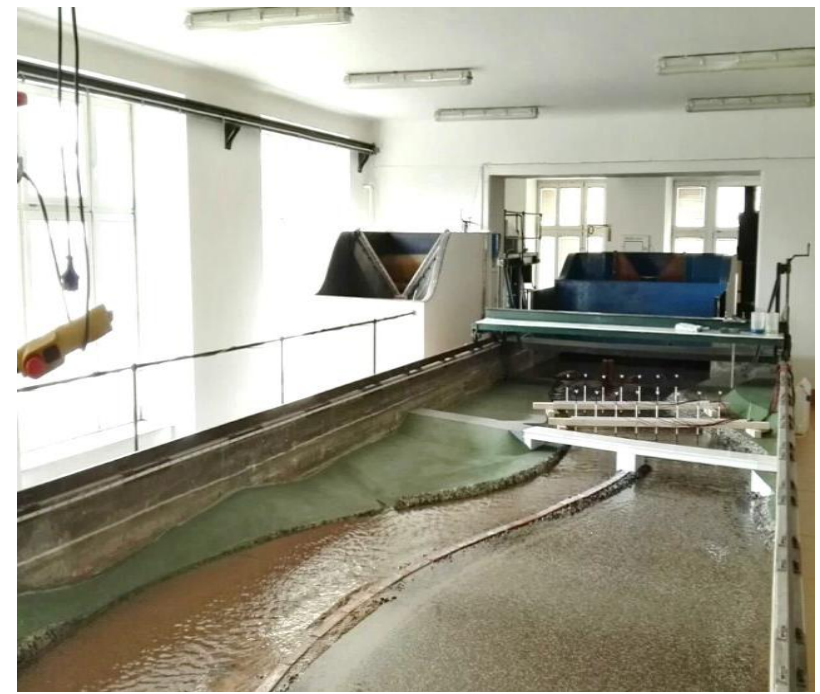

Figure 1 Physical model of a part of the river Opava on a scale $M_{l}=30$ built in the Brno University of Technology, Faculty of Civil Engineering, Institute of Water structure, Laboratory of water management research

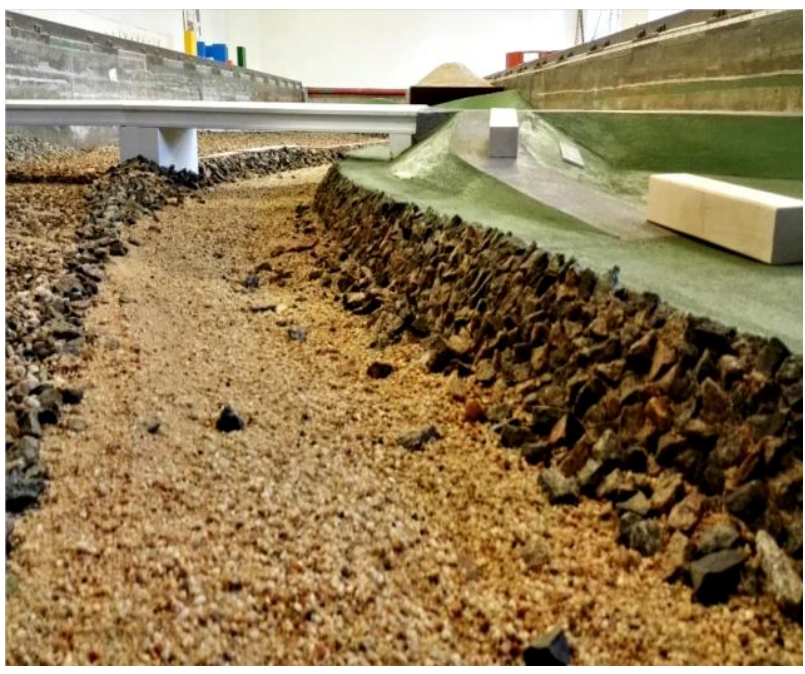

Figure 2 Physical model - movable bottom and banks

Model discharges are given by the scale of the model and the boundary conditions of similarity, discharge from $Q_{1}$ can be used for the river bed. Discharges smaller than $Q_{1}$ were used to determine the initiation of movement of fine grain fractions. A constant discharge corresponding to $Q_{5}$ was chosen to model the spread of pollution (Table 1, blue line). Water was supplied to the model from a laboratory recirculation system, in which its temperature and water level in the storage tank are measured.

\begin{tabular}{|c|c|c|}
\hline $\begin{array}{c}N \text {-year } \\
\text { flow }\end{array}$ & Prototype $\left[\mathrm{m}^{3} / \mathrm{s}\right]$ & Model $[1 / \mathrm{s}]$ \\
\hline$Q_{1}$ & 15.0 & 3.04 \\
\hline$Q_{5}$ & 65.5 & 13.3 \\
\hline$Q_{10}$ & 91.2 & 18.5 \\
\hline$Q_{20}$ & 121 & 24.6 \\
\hline$Q_{50}$ & 166 & 33.7 \\
\hline$Q_{100}$ & 206 & 41.8 \\
\hline
\end{tabular}

The model discharge is determined from the $Q / h$ characteristic of the Thomson weir and read from the LC display.

After each hydrodynamic loading of the model, its bottom was re-focused and the areas in which degradation and aggradation occurred were identified. During the experiment, the levels of the water surface were also focused in selected profiles, identical to the profiles for measuring the pollution concentration and water level (Fig. 3).

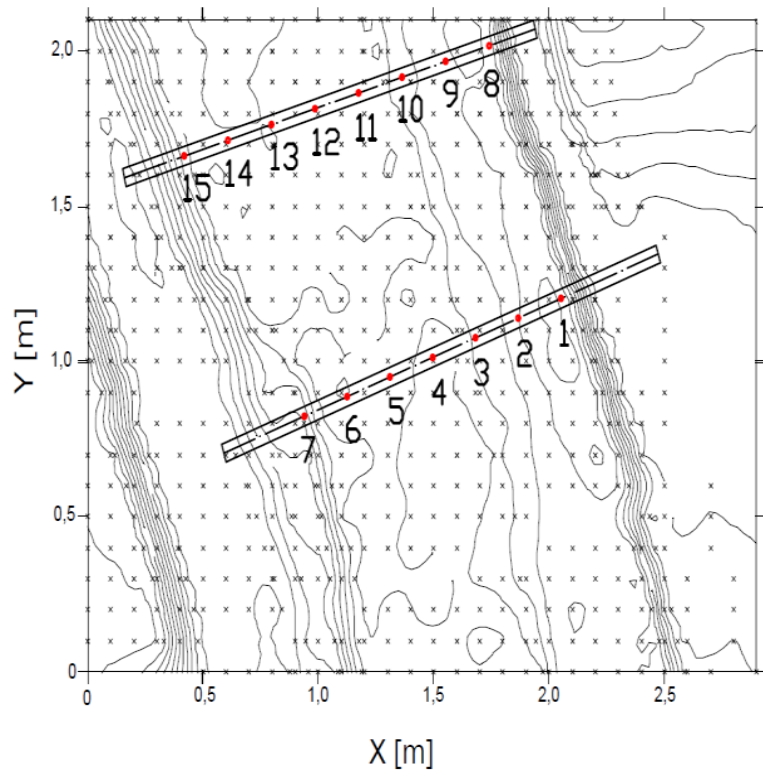

said discharge, the bottom was stabilized and the model was prepared for the implementation of the experiment of spreading pollution in the watercourse (Fig. 4).

\subsection{Choice of substance simulating pollution}

The substance for laboratory experiments simulating the spread of pollution on physical models of watercourses or reservoirs had to respect

- possibility to prepare an aqueous solution, 
- the regime of water flow in the stream (an issue related mainly to density and temperature changes),

- did not affect the measured values by changes in the background values, i.e. possible sticking to the walls of the model or to the bottom material

- and in the long run it did not participate in the destructive effects acting on the recirculation laboratory system, i.e. it was not primarily the cause of corrosion.

These requirements had to be verified by measurement with respect to the sensitivity of the designed measuring apparatus working with the Z-meter IV.

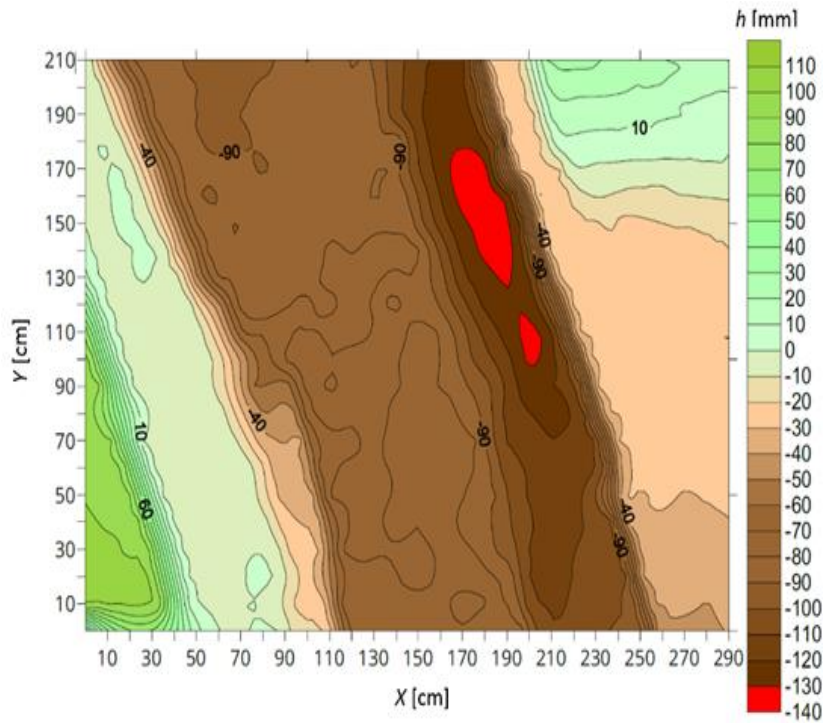

Figure 4 The isolines of the model bottom level $h$ after the hydrodynamic load

An aqueous solution of $\mathrm{NaCl}$ is often used to simulate the spread of pollution in physical models. Its advantage is the availability of economy in terms of stock. On the contrary, the disadvantage is the change of the measured background after application to the physical model, because salt crystals may appear on the unloaded model, and above all it may adversely affect the pumping technique and its circuits, where it can cause corrosion on metal elements. The goal of experiment was to verify an alternative substance that would meet the condition of availability and would not leave negative effects after application. For this reason, was chosen the substance Savo (solution of sodium hypochlorite), which is commonly used in households, and therefore, in addition to the condition of economic and quantitative availability, it also meets hygienic conditions. Aqueous solutions prepared from commercially available and inexpensive preparations Savo original, Savo gel and common salt $\mathrm{NaCl}$ were used and verified. An aqueous solution of the deep blue food colouring available under the trade name Brilliant Blue E133 was used to visualize the flow (Fig. 5).

\subsection{Measuring probes and apparatus}

The construction of measuring probes had to meet several basic specific requirements:

- sufficient rigidity to prevent possible oscillations when placed in a watercourse,

- easy manual handling of probes,

- $\quad$ ensuring point measurement in specified profiles,

- ensuring good contact of the measuring electrodes with the measured liquid,

- a sufficient number of probes to monitor areas of expected pollution,

- a uniform area of the measuring electrodes to reduce the uncertainty of the measurement of the electrical impedance caused by the contact of the electrode with the monitored liquid,

- inability air bubbles adhering, including air or others particles dissolved in water,

- not affecting the flow of the monitored liquid by placing the probe.

Ensuring the above requirements led to the construction of the probe from a flat double line represented by a pair of insulated copper conductors wires with a diameter of $2 \times 2 \mathrm{~mm}$, the insulation around each conductor is $1 \mathrm{~mm}$ thick. The diameter of one electrode is $4 \mathrm{~mm}$, the diameter of the probe is $8 \mathrm{~mm}$ and the axial distance of the measuring electrodes is $4 \mathrm{~mm}$ (Fig. 5).

During the construction of the probe, great attention had to be paid to the machining of the measuring electrodes, when the copper conductor was cut vertically and the insulation was free of any burrs, thus ensuring the same area of the measuring electrodes for all probes. Furthermore, it was necessary to eliminate the possibility of deformation of the velocity field by placing the probe in the flowing liquid. For this reason, the double insulated copper wire was bent at a right angle at the bottom. This caused the measuring part of the probe to be suspended in front of its guide part by $5 \mathrm{~cm}$.

The swelling of the water level by the guide part of the probe did not affect the water flow or the monitored simulated water pollution.

The total number of probes was 15 and they were installed in two rows in numbers 1 to 7 and 8 to 15 .

Due to fixed fixation and locking in the horizontal and vertical direction, the probes were mounted in two wooden prisms, the pollution concentration was measured in one horizontal level. 


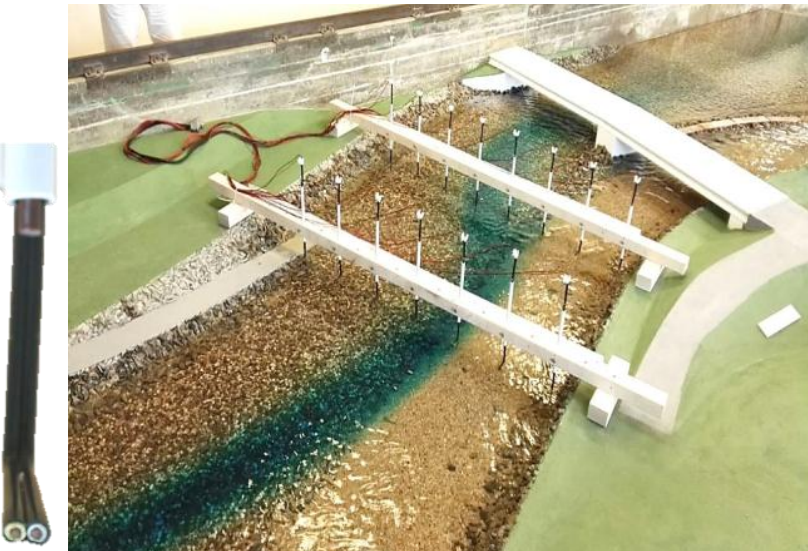

Figure 5 Detail of point measuring probes and their mounting on the model

The measuring apparatus (Fig. 6) with Z-meter IV device was realized by solving the project E! 7614 [15].

The electromagnetic properties $[16,17,18]$ of the test environment are recorded in the measured resistance $R[\Omega]$ and reactance $X[\Omega][9,10]$. The inverse value of electrical conductance $G$ [S], which was further worked with, was calculated from the measured value of resistance

$$
G=\frac{1}{R}
$$

The parameters of the Z-meter IV measurement were as follows for all experimental variants:

- $\quad$ measuring frequency $f=8 \mathrm{kHz}$,

- amplitude of measuring voltage $U=1 \mathrm{~V}$,

- measurement period $T=100 \mathrm{~ms}$,

- $\quad$ number of measurement repetitions $n=10$.

Other monitored variables were the temperature of the loading water $t_{\mathrm{H} 2 \mathrm{O}}=21,2{ }^{\circ} \mathrm{C}$ and the temperature of the air $t_{a}=27,6{ }^{\circ} \mathrm{C}$ in the laboratory measured by THERM 2285-2 device using temperature probe and the same device was used for point velocity measurement by laboratory propeller probe.

Water from the recirculation system was used to prepare the aqueous solutions for experiments on model (the reason was to maintain the same electrical conductivity and temperature in all experiments).

The salt weights were determined with KERN 822824 scales (weighing capacity up to $2 \mathrm{~kg}$, sensitivity 0.01 $\mathrm{g})$, the liquid substances were measured in calibrated measuring cylinders.

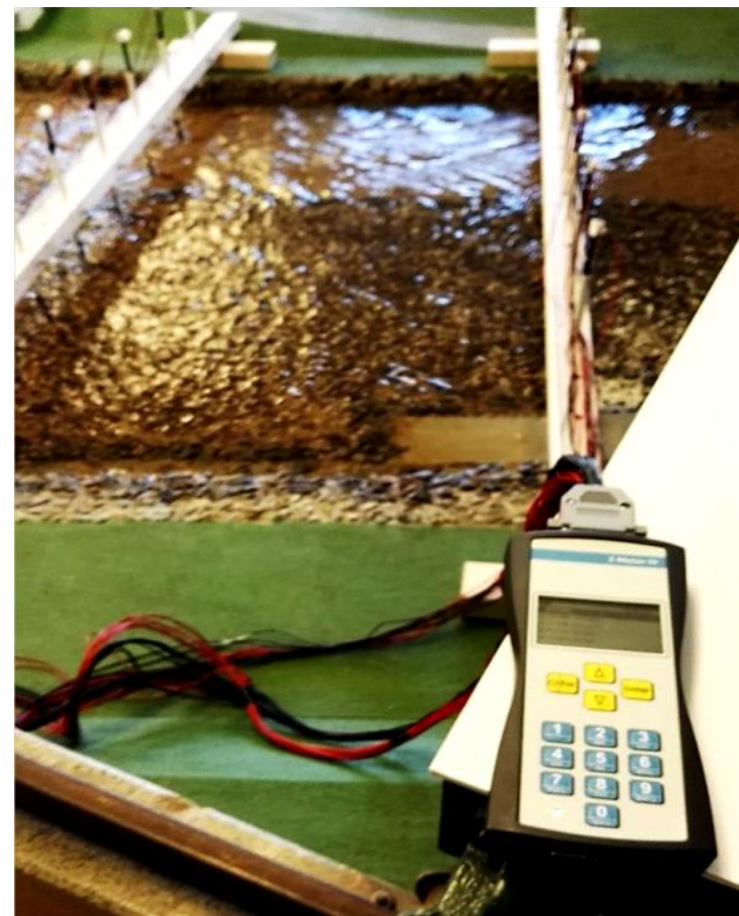

Figure 6 Z-meter IV device during measurement

\subsection{Probe calibration}

Calibration of probes means the determination of the dependence of the measured electrical conductance $G$ on the concentration $c$ of an aqueous solution of a given substance. Many measurements were performed for all selected substances.

However, their presentation is beyond the scope of the contribution, and therefore only an example of the procedure and results achieved for substance Savo original is given below (Fig. 7). From all tested, the substance was chosen due to the time duration of the experiment on physical model and its non-aggression towards the recirculation system and relatively quick disappearance from the environment in which it was used.

Distilled water was used to prepare a calibration aqueous solution of the individual substances in order to eliminate the measurement uncertainty due to the conductivity of the ions contained in the drinking water or in the water from the storage tank of the recirculation laboratory system.

Solutions were prepared and calibrated at the temperature $23^{\circ} \mathrm{C}$. 
$\rightarrow 1+-2 \rightarrow 3 \rightarrow-4 \rightarrow 5 \rightarrow-6 \rightarrow 7 \rightarrow-8 \rightarrow 9 \rightarrow 10 \rightarrow 11+12 \rightarrow 13 \rightarrow-14 \rightarrow-15$

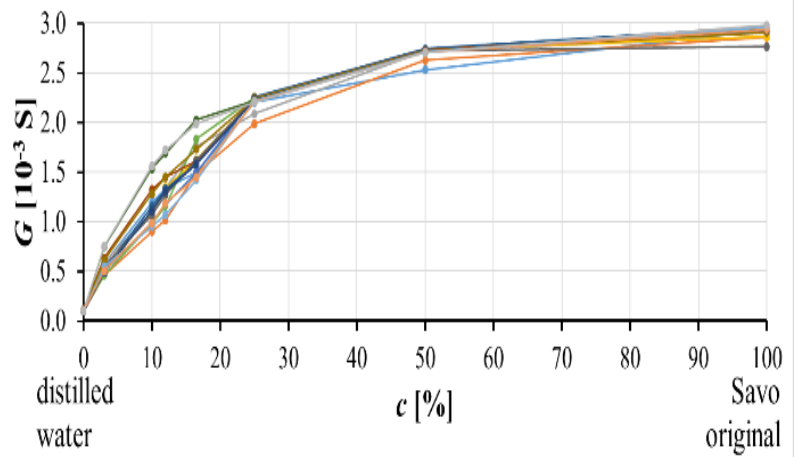

Figure 7 Dependence of electrical conductivity $G$ on the concentration $c$ of aqueous solution Savo original

(The number in legend is number of the probe in all similar results in this text.)

From the above characteristics, $1.7 \%$ variance can be stated between the maximum and minimum value of electrical conductance measured by individual probes in distilled water and $2.4 \%$ in Savo original. This result can be considered adequate due to the experiment of spreading pollution in the stream. It is obvious that the concentration of the aqueous solution Savo original the dependence shows a very good coefficient of determination (Table 2).

Table 2 The relationship $c=\mathrm{f}(G)$

\begin{tabular}{|c|c|c|c|c|}
\hline $\begin{array}{l}\text { probe } \\
\text { number }\end{array}$ & $\begin{array}{l}\text { relationship for } \\
\text { concentration } \\
\text { up to } 100 \%\end{array}$ & $\begin{array}{l}\text { coefficient of } \\
\text { determination }\end{array}$ & $\begin{array}{c}\text { relationship for } \\
\text { concentration } \\
\text { up to } 50 \%\end{array}$ & $\begin{array}{l}\text { coefficient of } \\
\text { determination }\end{array}$ \\
\hline 1 & $c=0.0011 G+6.9734$ & 0.96 & $c=0.003 \mathrm{G} \cdot 1.242$ & 0.97 \\
\hline 2 & $c=0.0013 \mathrm{G}+7.1151$ & 0.95 & $c=0.004 G \cdot 1.144$ & 0.98 \\
\hline 3 & $c=0.0012 G+6.4939$ & 0.94 & $c=0.003 \mathrm{G} \cdot 0.913$ & 0.99 \\
\hline 4 & $c=0.0014 G+8.0682$ & 0.97 & $c=0.004 G \cdot 1.053$ & 0.99 \\
\hline 5 & $c=0.0012 G+6.8674$ & 0.96 & $c=0.004 G \cdot 0.958$ & 0.99 \\
\hline 6 & $c=0.0013 \mathrm{G}+7.2968$ & 0.95 & $c=0.004 G \cdot 1.214$ & 0.98 \\
\hline 7 & $c=0.0012 G+7.6596$ & 0.87 & $c=0.004 G \cdot 0.801$ & 0.82 \\
\hline 8 & $c=0.0011 G+6.8039$ & 0.96 & $c=0.003 G \cdot 1.272$ & 0.98 \\
\hline 9 & $c=0.0012 G+7.7893$ & 0.92 & $c=0.004 G \cdot 1.042$ & 0.98 \\
\hline 10 & $c=0.0010 \mathrm{G}+6.9146$ & 0.92 & $c=0.003 \mathrm{G} \cdot 1.169$ & 0.98 \\
\hline 11 & $c=0.0013 \mathrm{G}+6.8794$ & 0.95 & $c=0.004 G \cdot 0.937$ & 0.99 \\
\hline 12 & $c=0.0009 \mathrm{G}+6.8671$ & 0.92 & $c=0.003 \mathrm{G} \cdot 1.013$ & 0.99 \\
\hline 13 & $c=0.0012 G+7.2245$ & 0.95 & $c=0.004 G \cdot 0.932$ & 0.99 \\
\hline 14 & $c=0.0011 G+7.1198$ & 0.94 & $c=0.004 G \cdot 0.837$ & 0.99 \\
\hline 15 & $c=0.0009 \mathrm{G}+6.7949$ & 0.93 & $c=0.003 \mathrm{G} \cdot 1.205$ & 0.98 \\
\hline
\end{tabular}

Therefore, for experiments on the physical model, an aqueous solution with the concentration of the substance Savo original on the middle of the range means $c=50 \%$ in a total volume of $0.015 \mathrm{~m}^{3}$ was prepared and dosed was below the water level in the channel of Opava river model. Furthermore, a test of the time changes of the values of electrical conductance $G$ was performed (Fig. 8), i.e. the determination of the fading time of the effect of the substance Savo on the measured background.

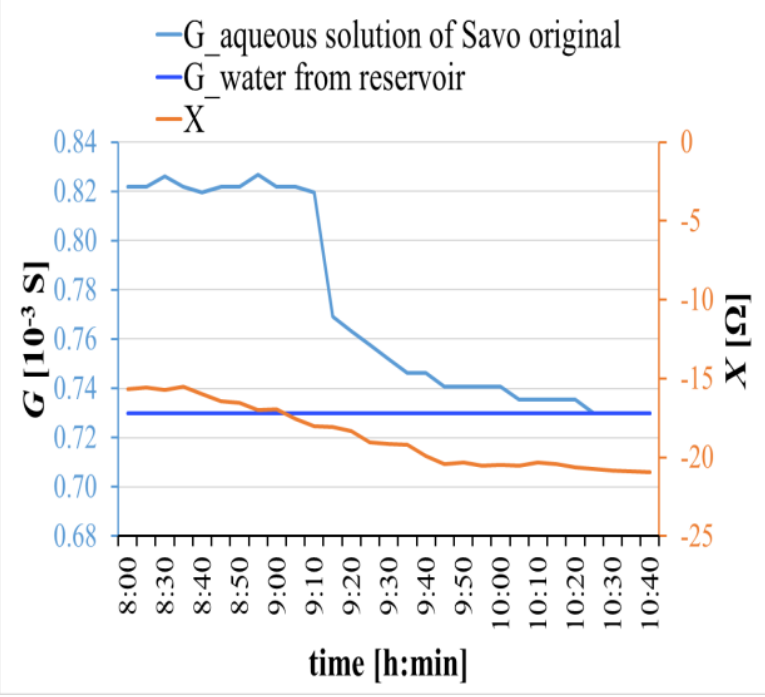

Figure 8 Time change of electrical conductance $G$ of aqueous solution $c=50 \%$ of Savo original prepared from water from the storage tank

Based on the achieved result, it can be stated that after about $2 \mathrm{~h}$, the $G$ values of the aqueous solution of Savo original were measured at the same level as for the water from the storage tank. This verified the assumption that the aqueous solutions of Savo original used would not affect the values observed in the experiment. On the other hand, they defined a time limit for its duration which can be about 70 minutes.

\section{RESULTS AND DISCUSSION}

The following section presents some of the results achieved in the implementation of experiments of the spread of pollution in the stream on physical model in laboratory conditions.

\subsection{The water surface level and point water velocity}

The water surface level and the point velocity (Fig. 9) was performed in identical coordinates as the measurement of the pollution concentration. The distances on the $X$-axis are related to the left wall of the river channel.

The lowest value of the point velocity was measured in the left overbank of the cross-section and ranged from $0.001 \mathrm{~m} / \mathrm{s}$ to $0.28 \mathrm{~m} / \mathrm{s}$. The highest value 
ranged

from

$0.30 \mathrm{~m} / \mathrm{s}$ to $0.47 \mathrm{~m} / \mathrm{s}$, and was determined in the channel.

This result confirms the deformation of the bottom of the model, which is most pronounced in the channel of the cross-section and the main line of pollution spread (Fig. 5 - dark blue colour).

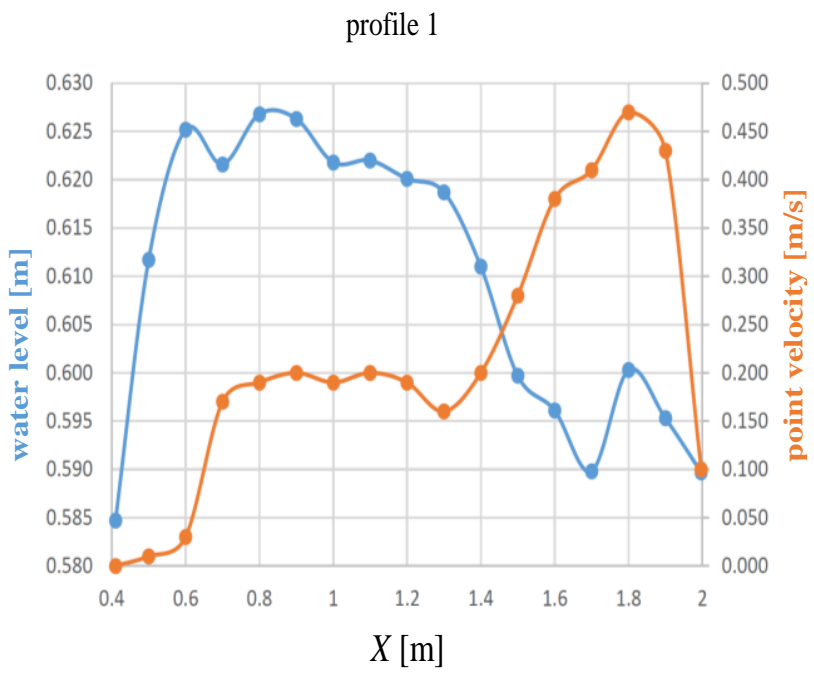

profile 2

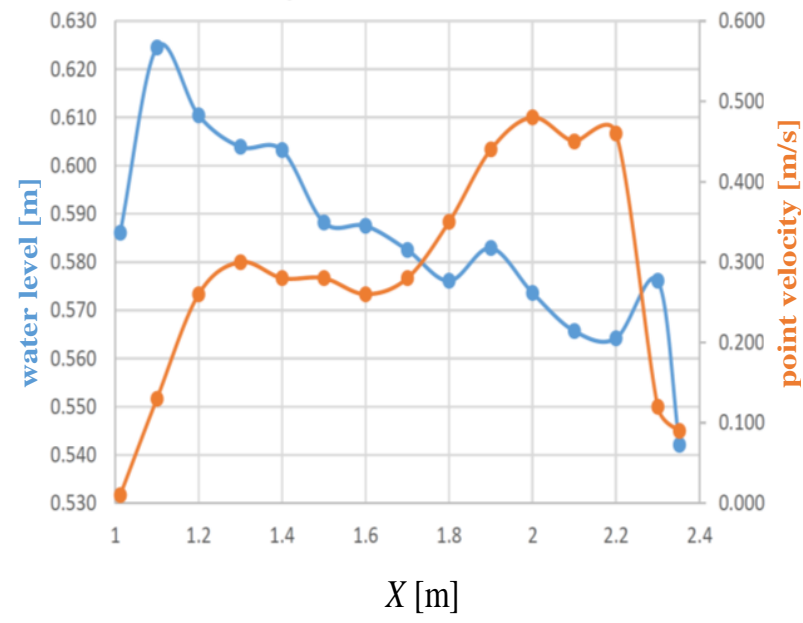

Figure 9 Example of measured water surface level and point velocity, $Q_{\text {model }}=0.0133 \mathrm{~m}^{3} / \mathrm{s}$,

\subsection{The electrical conductance of water from the storage tank}

The electrical conductance $G$ of the water flowing from the storage tank of the recirculation system was determined by individual probes (Fig. 10). Said measurement determined the so-called background value of the experiment, which further served to control and possibly eliminate changes in background values after the addition of a solution with a simulating substance.
From the above characteristics, a $46.1 \%$ variance can be stated between the maximum and minimum initial value of electrical conductance measured by individual probes. It can be assumed that the characteristics of the copper conductor used (the source was not one) and the machining of the probes during production contribute to the value of the said variance. Furthermore, it can be observed that the measured $G$ values are constant over time on some probes and some show a slight increase in the range of up to about $4.5 \%$. It is possible to assume that small impurities leached out of the moving bottom of the physical model, for example, contribute to this phenomenon. An approximately $8.5 \%$ increase in $G$ values over time is then determined for probe 3 and probe 6 .

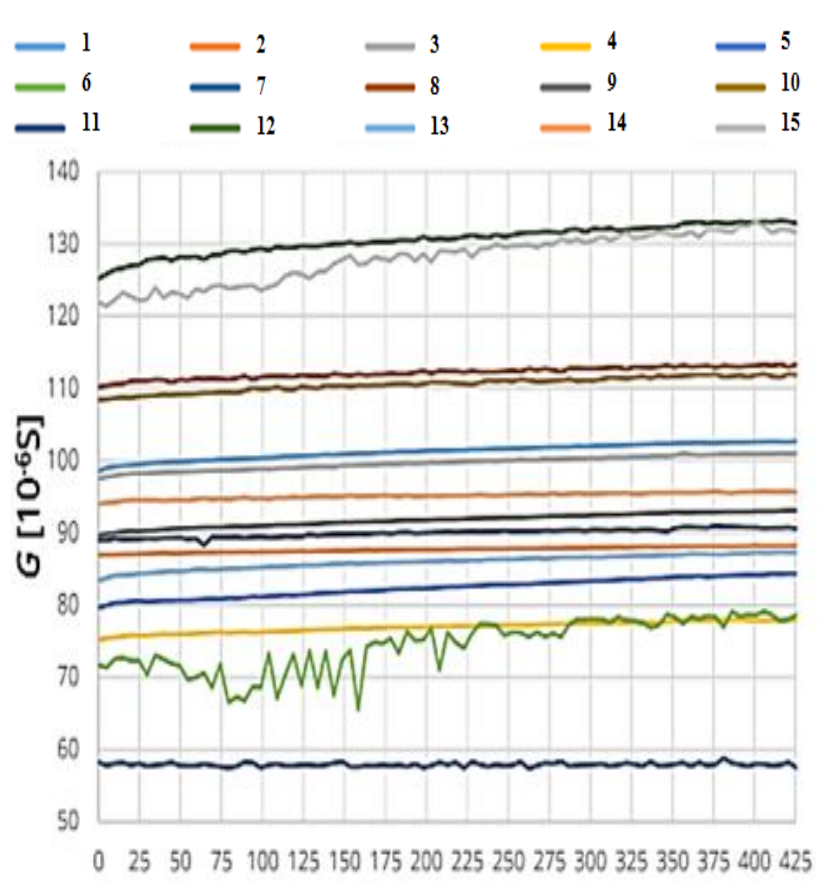

$t[s]$

Figure 10 Dependence of time change of electrical conductance of water, $Q_{\text {model }}=0.0133 \mathrm{~m}^{3} / \mathrm{s}$

On the other hand, the positive result is the fact that the mentioned characteristics did not show qualitative or quantitative changes in the repetitions of the experiment. At the same time, they confirmed that the substance Savo original had disappeared from the model. This ensured the same initial conditions for all experiments.

\subsection{Time change of electrical conductance during the application of a pollutant}

A substance, Savo original $c=50 \%$, simulating contamination was dosed below the surface into a steady 
flow of water to the model while respecting the density and temperature regime of the flow. The time change of electrical conductivity was measured in the determined profiles (Fig. 11).

The discontinuous loading of the watercourse by the simulated pollution may result in two significant peaks measured by probes 5,13 and a smaller peak measured by probe 14 (the position of the probes is evident from Fig. 5). These peaks were recorded at $55 \mathrm{~s}$ from the start of the measurement, while mainstream pollution was detected at $300 \mathrm{~s}$ from the start of the measurement and is evident on all probes located in the channel. It is also an interesting fact that both maxima measured by probe 13 show a deviation of only $1.7 \%$.

As a final step, the values of the detected electrical conductivity were converted according to Tab. 2 to the values of the simulated pollution concentration. The performed variants of the experiment, due to the configuration of the physical model, allow the compilation of graphical course or maps of pollution concentration for substance aqueous solution Savo original simulating the spread of pollution on a physical model of a watercourse.

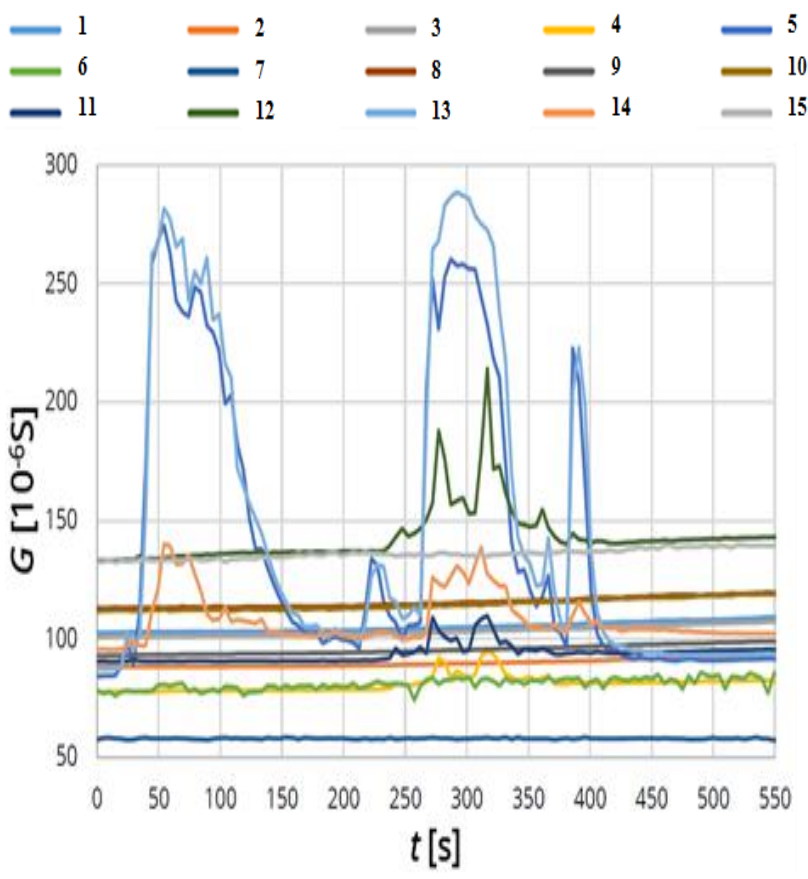

Figure 11 Example of measured $G$ time changes by the influence of pollutant in time, $Q_{\text {model }}=0.0133 \mathrm{~m}^{3} / \mathrm{s}, c$ $=50 \%$ Savo original

The conversion of the values of the electrical conductivity $G$ to the values of the concentrations $c$ was performed only for the active measuring probes located in the channel. The course of the absolute values of the detected concentration is plotted (Fig. 12). It is determined in such a way that the background value found in the evaluated variant of the experiment was first subtracted from the measured value $G$ and then the conversion to the concentration value was performed. It is obvious that in profile 1 the maximum value of the pollution concentration in the position of $1.32 \mathrm{~m}$ was recorded, which was also confirmed by visual observation during the application of the aqueous solution of the deep blue food colouring. In similar experiments, aqueous salt solutions are used by default to simulate the spread of pollution. Therefore, the course found in the application of aqueous $\mathrm{NaCl}$ solution is plotted in this final graph also.
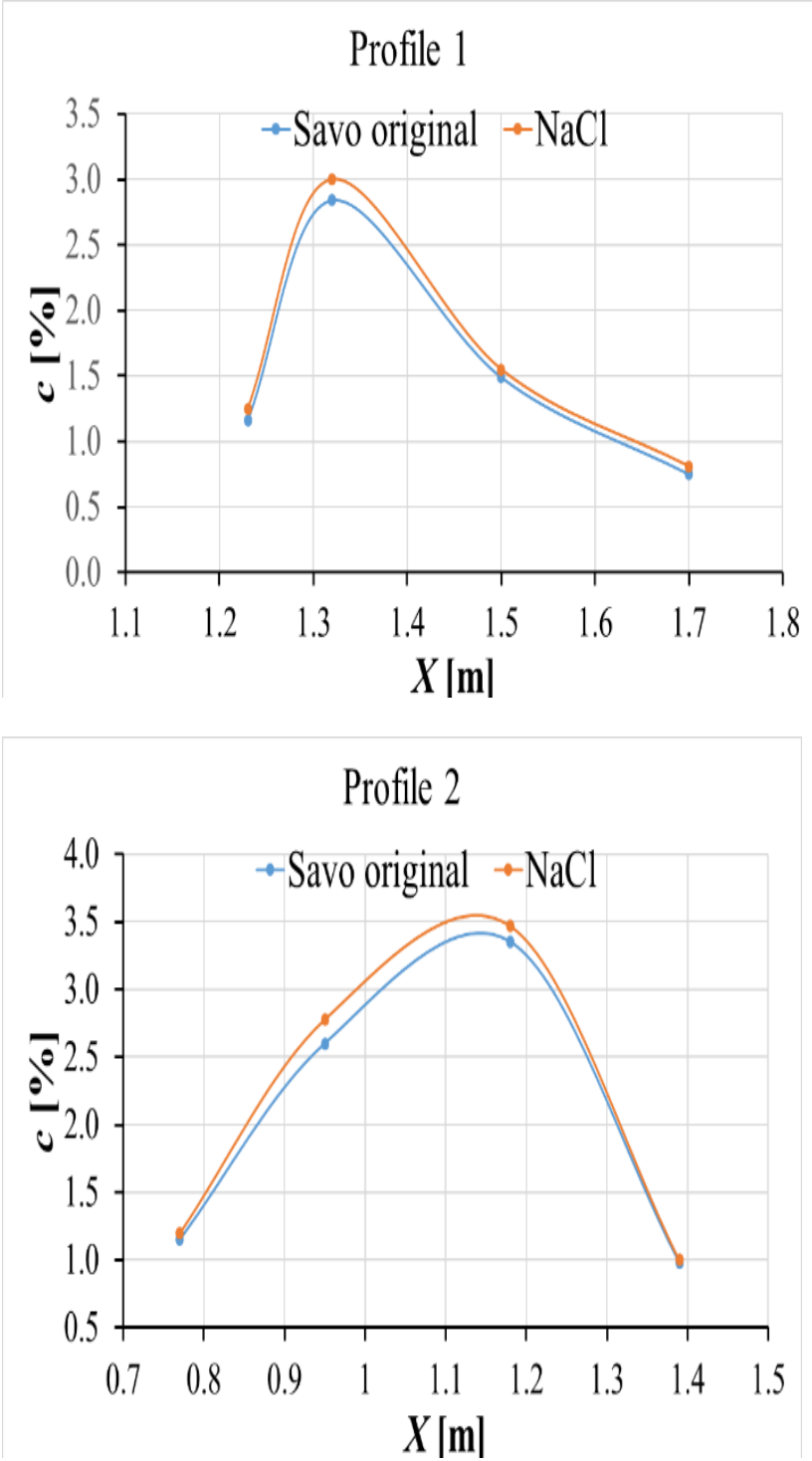

Figure 12 Example of the evaluated course of the concentration of the pollutants detected in the channel,

$$
Q_{\text {model }}=0.0133 \mathrm{~m}^{3} / \mathrm{s}
$$

From a qualitative and quantitative point of view, both concentrations curves of aqueous solutions of $\mathrm{NaCl}$ 
thin-plate weirs for small heads" and the sustainability of international project E!7614 of the EUREKA programme.

\section{REFERENCES}

[1] Ettema R., Arndt R., Roberts P., Wahl T., 2000. Hydraulics Modeling. Concepts and Practice. ASCE Reston. Virginia. ISBN 0-7844-0415-1.

[2] Novak P., Čábelka J., 1981. Models in Hydraulic Engineering: Physical Principles and Design Applications. Pitman Advanced Publishing Program. Boston-London-Melbourne.

Based on the achieved results, it is clear that the EIS method with the multiple frequency electrical impedance analyser Z-meter represent a certain suitable potential in the field of recognizing spread of the pollution in the stream.

Extensive laboratory research was performed on a physical model of a part of the Opava River, which is located in northern Moravia in the Czech Republic. Pollution was simulated by substances with specific requirements for their detectability through electrical conductance by Z-meter device, hygienic safety, commercial and financial affordability and nonaggressiveness to the laboratory pumping system.

The paper presents only partial results from extensive measurements, but they can provide guidance on the progress of work in similar research.

It can be stated that the advantage of the application of aqueous solutions of Savo-based fluids can be considered their disappearance from the physical model in about 2 hours. This is very positively reflected in the fact that they don't have or have negligible influence to measured values of electrical conductance, because of the background values of the model. However, the negative side may be the limitation of the duration of the experiments, i.e. the need to carry out short-term experiments in order to ensure the values stability of the applied aqueous solution.

Aqueous solutions of common salt are used as standard in physical modeling. Their indisputable advantage is a clearly identifiable change in the electrical conductivity of the measured medium, the disadvantage may be influencing the measured values by increasing the salinity of the flowing medium, leaching of salt crystals that may have adhered to some parts of the investigated physical model and last but not least corrosion.

\section{ACKNOWLEDGMENTS}

This paper has been created within the national project FAST-J-21-7329 "Flow over triangular-notch
[3] Yalin M. S., 1971. Theory of Hydraulic Models. The Macmillan Press Ltd., ISBN 978-1-349-00245-0. DOI 10.1007/978-1-349-00245-0.

[4] Barenblatt G. I., 2005. Scaling. self-similarity. and intermediate asymptotics. Cambridge University Press. ISBN 978-0-521-435222-2 transferred to digital printing 2009.

[5] Pařílková J., Zachoval Z., 2020. Past. Present and Future of the Laboratory of Water Management Research in Brno. Springer Nature Switzerland AG. ISSN 2364-8198. ISBN 978-3-030-18363-9.

[6] Azzarello E., Masi E., Mancuso S., 2012. Electrochemical Impedance Spectroscopy. Springer. editor Volkov A. G., Plant Electrophysiology. chapter 9. 205-223. DOI: 10.1007/978-3-642-29119-7_9.

[7] Grossi M., Riccỏ B., 2017. Electrical impedance spectroscopy (EIS) for biological analysis and food characterization: a review. Journal of Sensors and Sensor Systems. 6. p. 303-325. 2017. This work is distributed under the Creative Commons Attribution 3.0 License. https://doi.org/10.5194/jsss-6-303-2017.

[8] Yarlagadda R. K. R., 2010. Analog and Digital Signals and Systems. Springer Science \& Business Media. p. 243. ISBN 978-1-4419-0034-0.

[9] Pařílková J., Zachoval Z., Műnsterová Z., Jandora J., Mikulka J., Dušek J., Juřička D., Zydroń T., Gruchot A. T., Gomboš M., Pavelková D., Gjunsburgs B., Radzevicius A., Skominas R., 2020. Bode and Nyquist plots: Assistance in soil characterization. Journal of Marine Technology and Environment. Vol.2. ISSN 1884-6116.

[10] Pařílková J., Radkovský K., 2016. Z-meter IV User's Manual. p. 19. 
[11] Patočka M., 2006. Physical modeling of the spread of pollution in watercourses and methods of its monitoring. Diploma thesis. Brno University of Technology FCE.

[12] Zachoval Z., 2016. Hydraulic model research of sediment trap for bedload in reservoir of Nové Heřminovy dam. Final report. Brno University of Technology FCE.

[13] Marek O., 2018. Monitoring of the spread of pollution on the physical model of the watercourse. Bachelor's thesis. Brno University of Technology FCE.

[14] Boor B., Kunštátský J., Patočka C., 1968. Hydraulics for water management structures. SNTL Praha.

[15] Pařílková J., Pavlík J., 2013. A System of Monitoring of Selected Parameters of Porous Substances Using the EIS Method in a Wide Range of Applications. Project of applied science E!7614 in programme EUREKA.

[16] Rafiuddin M. Z. I., 2016. Preparation. characterization. electrical conductivity and dielectric studies of $\mathrm{Na}_{2} \mathrm{SO}_{4}$ and $\mathrm{V}_{2} \mathrm{O}_{5}$ composite solid electrolytes. Measurement. 81. p. 102-112.

[17] Brown F. T., 2006. Engineering System Dynamics. CRC Press. p. 43. ISBN 978-0-8493-9648-9.

[18] McDonald J. D., 2016. Electric Power Substations Engineering. Second Edition. CRC Press. p. 363. ISBN 978-1-4200-0731-2. 